\title{
VISUOSPATIAL NEGLECT IN LOVIS CORINTH'S SELF-PORTRAITS*
}

\author{
Olaf Blanke \\ Laboratory of Cognitive Neuroscience, Brain Mind Institute \\ Ecole Polytechnique Fédérale de Lausanne (EPFL), Swiss Federal Institute of Technology \\ Station 15, 1015 Lausanne, Switzerland; and \\ Department of Neurology, University Hospital, CH-1211 Geneva, Switzerland
}

\author{
I. Introduction \\ II. Mature Style-Late Style? \\ III. Hospitalization \\ IV. Rehabilitation \\ V. Self-Portraiture \\ VI. Drawings \\ VII. Paintings \\ VIII. Discussions \\ References
}

\begin{abstract}
The characteristics of styles vary continuously and resist a systematic classification into perfectly distinct groups. It is meaningless to ask exactly when ancient art ends and medieval begins. There are of course, abrupt breaks and reactions in art, but study shows that here too, there is often anticipation blending and continuity. Precise limits are sometimes fixed by convention for simplicity in dealing with historical problems or in isolating a type.... Through careful description and comparison and through formation of a richer, more refined typology adapted to the continuities in development, it has been possible to reduce the areas of vagueness and to advance our knowledge of styles.

(Heinrich Wölfflin, "Principles of Art History: The problem of the development of style in later art," 1915.)
\end{abstract}

\section{Introduction}

Lovis Corinth (1858-1925) is one of the great individualists in the history of painting who transcended both his own time and conventional classifications (Kuhn, 1925; Osten, 1955; Schröder, 1992; Uhr, 1990). Corinth's productive years spanned nearly half-a-century (1876-1925), and he studied at the academies in Königsberg,

*In memoriam of the 10th anniversary of the death of Dr. Otto-Joachim Grüsser. 